OPEN ACCESS

Edited by:

Prajwal Gurung,

The University of lowa, United States

Reviewed by:

David Arranz-Solís,

University of California, Davis,

United States

Xiaoyu $\mathrm{Hu}$,

University of Texas Southwestern Medical Center, United States

*Correspondence:

Musa A. Hassan musa.hassan@roslin.ed.ac.uk

Specialty section:

This article was submitted to Microbes and Innate Immunity,

a section of the journal

Frontiers in Cellular and Infection

Microbiology

Received: 27 April 2020

Accepted: 16 July 2020

Published: 20 August 2020

Citation:

Gossner A and Hassan MA (2020) Transcriptional Analyses Identify

Genes That Modulate Bovine

Macrophage Response to

Toxoplasma Infection and Immune

Stimulation.

Front. Cell. Infect. Microbiol. 10:437.

doi: 10.3389/fcimb.2020.00437

\section{Transcriptional Analyses Identify Genes That Modulate Bovine Macrophage Response to Toxoplasma Infection and Immune Stimulation}

\author{
Anton Gossner ${ }^{1}$ and Musa A. Hassan ${ }^{1,2 *}$ \\ ${ }^{1}$ Division of Infection and Immunity, The Roslin Institute, The University of Edinburgh, Edinburgh, United Kingdom, ${ }^{2}$ Centre \\ for Tropical Livestock Genetics and Health, The University of Edinburgh, Edinburgh, United Kingdom
}

The obligate intracellular parasite, Toxoplasma gondii, is highly prevalent among livestock species. Although cattle are generally resistant to Toxoplasma strains circulating in Europe and North America, the underlying mechanisms are largely unknown. Here, we report that bovine bone marrow-derived macrophage (BMDM) pre-stimulated with interferon gamma (IFN $\gamma$ ) restricts intracellular Toxoplasma growth independently of nitric oxide. While Toxoplasma promoted the expression of genes associated with alternative macrophage activation and lipid metabolism, IFN $\gamma$ abrogated parasite-induced transcriptional responses and promoted the expression of genes linked to the classical macrophage activation phenotype. Additionally, several chemokines, including CCL22, that are linked to parasite-induced activation of the $W n t / \beta$-catenin signaling were highly expressed in Toxoplasma-exposed naïve BMDMs. A chemical $W n t / \beta$-catenin signaling pathway antagonist (IWR-1-endo) significantly reduced intracellular parasite burden in naïve BMDMs, suggesting that Toxoplasma activates this pathway to evade bovine macrophage anti-parasitic responses. Congruently, intracellular burden of a mutant Toxoplasma strain (RH $\triangle A S P 5)$ that does not secrete dense granule proteins into the host cell, which is an essential requirement for parasite-induced activation of the $W n t / \beta$-catenin pathway, was significantly reduced in naïve BMDMs. However, both the Wnt/ $\beta$-catenin antagonist and RHASP $\triangle 5$ did not abolish parasite burden differences in naïve and IFN $\gamma$-stimulated BMDMs. Finally, we observed that parasites infecting IFN $\gamma$-stimulated BMDMs largely express genes associated with the slow dividing bradyzoite stage. Overall, this study provides novel insights into bovine macrophage transcriptional response to Toxoplasma. It establishes a foundation for a mechanistic analysis IFN $\gamma$-induced bovine anti-Toxoplasma responses and the counteracting Toxoplasma survival strategies.

Keywords: bovine toxoplasmosis, macrophages, RNA-sequencing, Toxoplasma, chemokine, Wnt/ $\beta$-cateninsignaling 


\section{INTRODUCTION}

Toxoplasma is a zoonotic protozoan parasite that infects virtually all warm-blooded vertebrates and is perhaps the most successful and widespread human pathogen. It is the leading cause of encephalitis and death in HIV/AIDS patients (Basavaraju, 2016) and is ranked 4th among foodborne parasites with the greatest global impact (FAO/WHO, 2014) and contributors to years lived with disability and disability-adjusted life years per million persons (Gkogka et al., 2011). Toxoplasma undergoes sexual reproduction exclusively in cats while asexual reproduction can occur in any intermediate host, including humans and farmed animals. Definitive-to-intermediate host parasite transmission occurs via ingestion of oocysts from infected cat feces, while transmission between intermediate hosts can occur through the consumption of contaminated food products or vertically from mother to fetus (Hill and Dubey, 2002). Although Toxoplasma infections in healthy individuals are mostly asymptomatic, severe disease or even death, often caused by damage to the brain or other organs, can occur in immunocompromised or congenitally infected individuals (Hill and Dubey, 2002). Toxoplasma typically establishes lifelong chronic infection in healthy intermediate hosts by encysting, after an initial phase of rapid intracellular proliferation and cell-cell spread, in the central nervous system and muscle tissues (Hill and Dubey, 2002). To do this, the parasite must carefully regulate immune activation and host cell anti-Toxoplasma effector mechanisms.

Toxoplasma invades host cells mostly through an active process powered by parasite-generated actin motor activity to form a specialized non-fusogenic parasitophorous vacuole (PV) (Fleckenstein et al., 2012) that helps the parasite avoid host cell immune surveillance (Morisaki et al., 1995). In phagocytic cells, such as macrophages, the parasite can also be taken up by phagocytosis and, sometimes the phagocytosed parasites can exit the phagosome to form a PV (Zhao et al., 2014). Besides hiding within the PV, the parasite also evades host cell immunity by sequentially discharging several effector proteins that modulate a variety of host immune and metabolic processes, including the inflammatory pathway (Hunter and Sibley, 2012). Generally, effective host anti-Toxoplasma responses are dependent on the production of interleukin (IL)-12 (Gazzinelli et al., 1994) by macrophages and dendritic cells (Gazzinelli et al., 1994). IL-12 in turn activates natural killer (NK) and $\mathrm{T}$ cells to secrete interferon gamma (IFN $\gamma$ ) (Gazzinelli et al., 1993, 1994), a pro-inflammatory cytokine that activates several anti-Toxoplasma effector mechanisms such as the interferon-regulated GTPases (IRGs) in mice (Zhao et al., 2009), reactive nitrogen/oxygen intermediates (Scharton-Kersten et al., 1997), tryptophan degradation and cell death in human cells (Pfefferkorn, 1984; Niedelman et al., 2013), and inflammasome activation (Cirelli et al., 2014). In return, Toxoplasma has evolved several mechanisms to counteract the IFN $\gamma$-induced host defenses, including the secretion of effectors proteins from specialized apical organelles that co-opt host transcription and signaling pathways to control host cell responsiveness to inflammatory signals (Jensen et al., 2011; Koshy et al., 2012; Bougdour et al., 2013; He et al., 2018).
Besides producing the IL12 that primes IFN $\gamma$ secretion by $\mathrm{NK}$ and T cells, macrophages are also the preferred intracellular niche for the fast-dividing parasite stage (Jensen et al., 2011). Thus, the innate defenses triggered by monocytes/macrophages are key to toxoplasmosis pathogenesis in humans and rodents (Channon et al., 2000; Dunay and Sibley, 2010; Gregg et al., 2013; Tosh et al., 2016; Song et al., 2017). Besides killing microbes, including Toxoplasma, macrophages can also initiate adaptive immune responses (van de Vosse et al., 2009; Thi et al., 2012). Human and mouse models show that upon the engagement of surface signaling receptors or pattern recognition receptors (PRRs) such as, toll-like (TLRs), RIGI-like (RLRs), and the cytosolic NOD-like (NLRs) receptors by conserved pathogen-associated molecular patterns (PAMPs) such as, lipopolysaccharide (LPS) or immune factors, including cytokines, macrophages assume different activation phenotypes. The most extreme classical [M1, M(IFN $\gamma)]$ and the alternative [M2, M (IL-4)] phenotypes are separated by several intermediate activation states (Murray et al., 2014). The M1 phenotype, which can be induced by IFN $\gamma$, is highly microbicidal and characterized by the production of reactive oxygen and nitrogen intermediates such as nitric oxide (NO), and a range of proinflammatory cytokines and chemokines, such as Tumor necrosis factor (TNF) alpha (De Paoli et al., 2014; Murray et al., 2014). In contrast, the M2 phenotype, which is induced by IL-4 and IL13 and is important for regulating inflammation, is characterized by the production of anti-inflammatory cytokines and growth factors (Sindrilaru and Scharffetter-Kochanek, 2013). The general hypothesis is that macrophage activation phenotypes, which are underpinned by discrete transcriptional programs (Hassan et al., 2015), provide a high degree of plasticity that is exploited by some intracellular pathogens, including Toxoplasma and Mycobacteria, to turn this potentially hostile host cell into a favorable replication niche (Price and Vance, 2014). Although effective host response to Toxoplasma require the induction of inflammation, characterized by classical macrophage activation, Toxoplasma promotes its survival in macrophages by secreting effector proteins to dampen inflammatory responses and favor alternative macrophage activation (Jensen et al., 2011). Indeed, Toxoplasma strain differences in virulence in mice is partly due to strain differences in inducing alternative macrophage activation (Jensen et al., 2011), while host differences in susceptibility to Toxoplasma is due in part to differences in macrophage activation phenotypes after infection (Jensen et al., 2011, 2013). Therefore, to devise strategies to improve the early defense against Toxoplasma and a variety of intracellular pathogens, it is important to understand the molecular mechanisms underpinning macrophage response to Toxoplasma and/or immune effector proteins, such as cytokines.

Toxoplasma is common in many species of livestock, including cattle. Compared to other livestock species, such as sheep and pigs, cattle are highly resistant to Toxoplasma and rarely transmit the parasite to other intermediate hosts (Dubey, 1986; Esteban-Redondo and Innes, 1997). Unlike sheep and pigs, natural Toxoplasma infection in cattle is mostly asymptomatic and does not appear to result in abortion. However, the molecular factors and mechanisms that modulate bovine-Toxoplasma 
interactions, which can be exploited to enhance resistance in other ruminants, are ambiguous. Although IFN $\gamma$ is central to anti-Toxoplasma responses in virtually all vertebrates, the role of this cytokine, and the mechanism underpinning, bovine resistance to Toxoplasma is equivocal. In the present study we sought to determine the role of IFN $\gamma$, and host genes associated with effective bovine macrophage response to Toxoplasma. We performed RNA-sequencing on naïve or IFN $\gamma$-stimulated bovine bone marrow derived macrophages (BMDMs) that were either unexposed or exposed to a Toxoplasma strain that is highly virulent in laboratory inbred mice $(\mathrm{RH})$ for $24 \mathrm{~h}$. Analysis of the datasets provides novel insights into the Toxoplasmainduced transcriptional responses in naïve and pre-stimulated BMDMs. We report that IFN $\gamma$ enhances bovine BMDMs anti-Toxoplasma responses and that, despite producing large amounts of nitric oxide, bovine macrophages restrict Toxoplasma independently of nitric oxide. Toxoplasma induces the $\mathrm{Wnt} / \beta$ catenin signaling pathway and the expression of several antiinflammatory chemokines and arginine metabolism in naïve BMDMs. On the other hand, to survive in IFN $\gamma$-primed BMDMs, the parasite expresses mostly genes that are associated with its slow dividing bradyzoite stage.

\section{MATERIALS AND METHODS}

\section{Parasites}

The type I Toxoplasma strain ( $\mathrm{RH}$ ) engineered to express green fluorescent protein (GFP) and firefly luciferase has previously been described (Jensen et al., 2013). The RH $\triangle A S P 5$ (Hammoudi et al., 2015) was a generous gift from Dr. Mohamed-Ali Hakimi (INSERM). All parasite strains were maintained by serial passage on confluent human foreskin fibroblast (HFF) monolayer.

\section{Primary Bone Marrow Derived Macrophages (BMDMs)}

Marrow cells were flushed from the ribs of three $(n=3)$ $\sim 2$ year old calves using phosphate buffered saline (PBS, Invitrogen). The cells were centrifuged at $500 \times \mathrm{g}$ for $5 \mathrm{~min}$ at $4^{\circ} \mathrm{C}$ and re-suspended in red cell lysis buffer (Sigma) and incubated on ice for $5 \mathrm{~min}$. Next, the cells were passed through a $70 \mu \mathrm{m}$ cell strainer (BD Biosciences) and centrifuged at $500 \times \mathrm{g}$ for $5 \mathrm{~min}$ at $4^{\circ} \mathrm{C}$. Cells from each calf were subsequently differentiated into macrophages in $10 \mathrm{~cm}$ non-tissue culture petri dishes (Corning) in RPMI 1640 (Sigma-Aldrich) supplemented with heat-inactivated 20\% fetal bovine serum (FBS, Thermo Fisher Scientific), GlutaMAX (Thermo Fisher Scientific), penicillin/streptomycin (Thermo Fisher Scientific), and recombinant human CSF1 $\left(10^{4} \mathrm{U} / \mathrm{ml}\right.$; a gift from Chiron, Emeryville, CA) for 10 days as previously described (Young et al., 2018).

\section{In vitro Measurements}

BMDMs from each calf were detached using a cell scraper, washed, counted, and seeded separately in triplicates in 96well plates at a density of $10^{5}$ cells/well. The BMDMs were left unstimulated (naïe) or stimulated with: recombinant bovine IFN $\gamma(100 \mathrm{ng} / \mathrm{mL})$, lipopolysaccharide (LPS) from Salmonella enterica serotype Minnesota Re 595 (Sigma-Aldrich, 100 ng/mL), or a combination of IFN $\gamma(100 \mathrm{ng} / \mathrm{mL})$ and LPS $(100 \mathrm{ng} / \mathrm{mL})$ with or without aminoguanidine (final concentration of $500 \mu \mathrm{M}$ ) and incubated at $37^{\circ} \mathrm{C}$ in $5 \% \mathrm{CO}_{2} .24 \mathrm{~h}$ post-stimulation, cell free supernatants were collected for Griess reagent-based nitric oxide assay, as previously described (Young et al., 2018), and cell viability, using the CellTiter $96^{\circledR}$ Aqueous One Solution Cell Proliferation kit (Promega) according to the manufacturer's recommendations. Freshly lysed parasites (by sequential passage through $25 \mathrm{G}$ and $27 \mathrm{G}$ needles) were passed through a $5 \mu \mathrm{m}$ filter to remove HFFs, counted, diluted in RPMI, and added to the BMDMs at a multiplicity of infection (MOI) 1 for $24 \mathrm{~h}$ before luciferase activity was measured using a luciferase assay kit (Promega) according to the manufacturer recommendations.

\section{RNA Sequencing and Analysis}

$2 \times 10^{6}$ BMDMs from each calf were seeded in 6-well plates and left unstimulated or stimulated with $\operatorname{IFN} \gamma(100 \mathrm{ng} / \mathrm{mL})$ for $\sim 18 \mathrm{~h}$ at $37^{\circ} \mathrm{C}$ in $5 \% \mathrm{CO}_{2}$. Next, the media was replaced with fresh media containing Toxoplasma at a MOI 1 and incubated further for $\sim 18 \mathrm{~h}$. Fresh media was added to the non-infected control BMDMs. At the end of the incubation period, total RNA was isolated from each BMDM sample using QIAzol ${ }^{\circledR}$ Lysis Reagent and miRNeasy Mini Kit (Qiagen) according to the manufacturer recommendations. RNA quality and integrity were assessed on the Agilent 2200 TapeStation using an Agilent RNA ScreenTape and quantified using a Qubit RNA BR Assay Kit and Fluorometer. RNA-seq libraries were generated and sequenced by Edinburgh Genomics. All libraries were prepared using the Illumina TruSeq Stranded library protocol for total RNA libraries (Part: 15031048, Revision E). Briefly, polyA-tail enrichment (Dynabeads mRNA Purification Kit; Invitrogen) was performed on the total RNA and the mRNA fragmented into 200-400 base-pairs, and reverse transcribed into cDNA before Illumina sequencing adapters were added to each end. Twelve barcoded libraries were multiplexed and sequenced on a single S2 sequencing lane on the Illumina NovaSeq 6000 machine to yield $\sim 60$ million 50 bp high quality strand-specific paired reads per sample. Reads were pseudoaligned to the Ensembl bovine genome (ARS-UCD1.2) using Kallisto v.0.46.0 (Bray et al., 2016) with 100 bootstraps to generate transcript-level expression estimates as transcripts per million (TPM) as previously described (Young et al., 2018). Gene-level differential expression analysis was performed in sleuth as previously described (Pimentel et al., 2017). TPM values derived from pseudoalignment of RNA-seq reads to the GT1 genome (ToxoDB.org) were used as input in sleuth to identify differentially expressed Toxoplasma genes.

\section{Quantitative Real-Time PCR}

One microgram of total RNA from each BMDMs sample was reverse transcribed using Superscript III (Thermo Fisher Scientific), $10 \mathrm{mM}$ dNTP mix (Thermo Fisher Scientific) and Oligo (dT) ${ }_{12-18}$ Primer (Thermo Fisher Scientific) according to the manufacturer's instructions. Gene-specific primers (Table 1) were designed using Primer-BLAST (Ye et al., 2012). All primers were commercially synthesized by Thermo Fischer Scientific. Quantitative real-time RT-PCR (qPCR) was performed in a 
TABLE 1 | Primer sets for qPCR validation of representative differentially expressed genes.

\begin{tabular}{|c|c|c|c|}
\hline Symbol & Primer 1 forward & Primer 1 reverse & $\begin{array}{l}\text { Amplicon } \\
\text { length }\end{array}$ \\
\hline C1R & GGTGCAGGATCAAGGACTGC & GTGTGCATCTTGTAGAAGGGCT & 136 \\
\hline ISG15 & GACCTGACGGTGAAGATGCTA & ATCTTCTGGGCGATGAACTGC & 98 \\
\hline PSMB8 & $\begin{array}{l}\text { TGTCAATATGTACCACAT } \\
\text { GAAGGAG }\end{array}$ & CACCATCACTGACTGGCCTC & 102 \\
\hline SGK1 & GCCAAGGATGACTTATGGAGA & AGGATCAAAGTGTCGCAGG & 138 \\
\hline IRF1 & AGGACATCATGAAGCTCTTGGA & GCTCCTCCTTGCAACTGAACT & 129 \\
\hline GBP5 & CCAGGAAAGGAATACAGGCTGA & TTCCATTGCTGTGAGAGCCAG & 107 \\
\hline RSAD2 & GTGGTTCCAGAAGTACGGTGA & СTTПTCCTTGACCACGGC & 103 \\
\hline$C F B$ & CTTGCAAAGGTGATTCTGGTGG & CGCTTGCAAACATCCACGAC & 100 \\
\hline GBP1 & СTCTCAAACTGCAGGAACAGTC & $\begin{array}{l}\text { TGCTITGGATAAGAGT } \\
\text { GACCAG }\end{array}$ & 175 \\
\hline CXCL10 & $\begin{array}{l}\text { TCCTCGAACACGGAAAGA } \\
\text { GGCATA }\end{array}$ & $\begin{array}{l}\text { AGCTGATATGGTGACTGG } \\
\text { CTTGGT }\end{array}$ & 164 \\
\hline CCL22 & CGGGACTACATCCGTTACCC & CAGCACAGATCTCTCGGTCC & 121 \\
\hline $\mathrm{CCl} / 24$ & GCAGGAGTGATCTTCACCACC & TAGCGGAGGCTTTCTTCTGC & 115 \\
\hline$S D H A$ & ACCTGATGCTITGTGCTCTGC & CCTGGATGGGCTTGGAGTAA & 126 \\
\hline GAPDH & GGTGATGCTGGTGCTGAGTA & TCATAAGTCCCTCCACGATG & 265 \\
\hline
\end{tabular}

Rotor-Gene Q real-time PCR cycler (Qiagen) using FastStart Universal SYBR Green Master (Rox) in final volume of 20 $\mu \mathrm{L}$. The linearity and efficiency of qPCR amplification was determined for each primer pair using a standard curve generated by a serial dilution of cDNA pooled from all the samples. All reactions were performed in duplicate and "no template" controls included for each gene. Agarose gel electrophoresis was used to confirm product sizes and melt curve analysis confirmed specificity of amplification. Data were analyzed using the $2^{-\Delta \Delta \mathrm{Ct}}$ method and statistical analyzed performed on the $\Delta \mathrm{Ct}$ values. qPCR was performed on parasite DNA as previously described (Li et al., 2000).

\section{RESULTS}

\section{IFN $\gamma$ Induces Restriction of Toxoplasma Growth in Bovine Macrophages Independently of Nitric Oxide}

To determine whether IFN $\gamma$ is essential for the control of Toxoplasma growth in bovine macrophages, we exposed naïve or IFN $\gamma$-stimulated bovine bone marrow-derived macrophages (BMDMs) to a luciferase-expressing type I Toxoplasma strain (RH) for $24 \mathrm{~h}$ and measured luciferase activity, a proxy for parasite burden (Hassan et al., 2015). In murine macrophages, IFN $\gamma$ is known to require a second stimulant, such as LPS or TNF, to effectively restrict Toxoplasma (Sibley et al., 1991; Hassan et al., 2015). Therefore, we included in our experiments, BMDMs that were pre-stimulated with IFN $\gamma+$ LPS. As expected, there was reduced intracellular parasite burden in BMDMs prestimulated with IFN $\gamma$ or IFN $\gamma+$ LPS, relative to naïve BMDMs (Figure 1A). However, there were no significant differences in parasite burden between IFN $\gamma$ - and IFN $\gamma+$ LPS-stimulated BMDMs, suggesting that IFN $\gamma$ alone can sufficiently induce anti-Toxoplasma activities in bovine BMDMs. A quantitative real-time polymerase chain reaction (qRT-PCR) analysis of parasite DNA (Li et al., 2000) confirmed the intracellular parasite burden differences between naïve and IFN $\gamma$-stimulated BMDMs (Figure 1B).

Previously, others and we reported that Nitric oxide (NO), a product of the inducible nitric oxide synthase (iNOS or NOS2)-catalyzed L-arginine metabolism (MacMicking et al., 1997), is a major IFN $\gamma$-induced effector against intracellular Toxoplasma growth in murine BMDMs (Hassan et al., 2015). In addition, bovine BMDMs stimulated with LPS and/or IFN $\gamma$ are reported to produce significantly more NO than ovine or equine BMDMs (Denis et al., 2005; Young et al., 2018), which are susceptible to Toxoplasma. Thus, we postulated that NO inhibits Toxoplasma growth in bovine IFN $\gamma$-stimulated BMDMs. Consequently, we determined whether IFN $\gamma$ alone can induce NO production in bovine BMDMs and whether the levels of the induced NO correlate with intracellular parasite burden in the pre-stimulated BMDMs. Unlike IFN $\gamma$, IFN $\gamma+$ LPS induced a 34 -fold increase in $\mathrm{NO}$, relative to unstimulated BMDMs (Figure 1C). Thus, unlike murine BMDMs, $\mathrm{NO}$ is dispensable for IFN $\gamma$-induced Toxoplasma growth restriction in bovine BMDMs.

\section{Toxoplasma Induces a Robust Bovine Macrophage Transcriptional Response}

To gain mechanistic insight into bovine innate immune response to Toxoplasma, we leveraged high throughput RNA-sequencing to profile the transcriptional landscape of bovine BMDMs that were left unstimulated (naïve) or pre-stimulated with IFN $\gamma$ before being exposed to Toxoplasma for $24 \mathrm{~h}$. Transcriptional analysis was also performed on uninfected controls. Downstream analysis was restricted to genes that were differentially expressed by more than 2 -fold change and had at least 10 reads that uniquely aligned to the genome in at least two samples when compared the uninfected naïve BMDMs. In total, 1,349 unique genes were differential expressed in at least one condition, of which 887 were differentially expressed in a condition-specific manner (Figure 2A and Supplementary Table 1). Unlike IFN $\gamma$ that interacts mainly with the IFN $\gamma$ receptors to induce the expression of several IFN $\gamma$-specific genes (ISGs), Toxoplasma is likely to interact with many, yet to be defined, bovine BMDM pattern recognition receptors to induce bovine gene expression. Indeed, there were more differentially expressed genes that were unique to naïve BMDMs exposed to Toxoplasma ( $\mathrm{RH}$-specific) than in the uninfected IFN $\gamma$-stimulated BMDMs, (657 vs. 134, respectively; Hypergeometric $P$-value $\leq 0.05$ ). Interestingly, only 96 genes were differentially expressed exclusively in IFN $\gamma$ stimulated BMDMs exposed to Toxoplasma (IRH-specific), suggesting that pre-stimulation with IFN $\gamma$ abrogates a majority of Toxoplasma-induced transcriptional changes in the BMDMs (Figure 2A). The variable expression of most genes (579/657, $\sim 88 \%$ ), including immunoregulatory genes such as Krüppel-like factor 4 (KLF4) and Ornithine decarboxylase (ODC1), in the $\mathrm{RH}$ BMDMs was due to increased transcript abundance in the Toxoplasma-exposed BMDMs, rather than a downregulation of innately expressed genes, as revealed by hierarchical clustering 

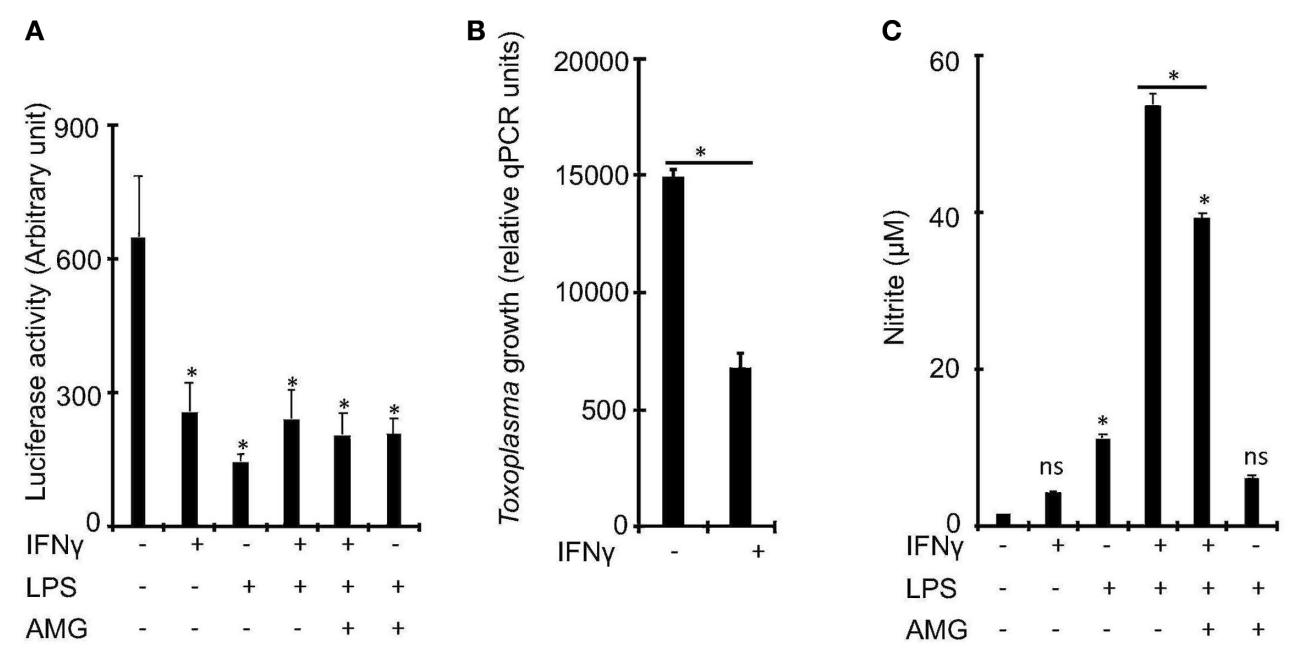

FIGURE 1 | IFN $\gamma$ restricts Toxoplasma growth in bovine bone marrow derived macrophages (BMDMs) independently of inducible nitric oxide. (A) Bovine BMDMs stimulated with IFN $\gamma(100 \mathrm{ng} / \mathrm{mL})$ and/or LPS $(100 \mathrm{ng} / \mathrm{mL})$ for $\sim 18 \mathrm{~h}$ have reduced intracellular parasite burden, relative to control, which did not change with the addition of aminoguanidine (AG), a scavenger for reactive oxygen/nitrogen species, to the cell culture medium. (B) Reduced intracellular parasite burden in IFN $\gamma$-simulated BMDMs was confirmed using a quantitative real-time PCR (qPCR) on parasite DNA as previously described (Li et al., 2000). (C) Similar to murine, BMDMs, IFN $\gamma$ alone, without a second stimulant, does not sufficiently induce NO in bovine BMDMs. Data are average value \pm s.d. of three replicates. $P$-values of two-tailed unpaired Student's $t$-test; ${ }^{*} p<0.05$ and $n s=$ not significant. Data are representative of three independent experiments.

(Figure 2B), suggesting that effective response to the parasite is inducible. Three hundred and forty genes, including several inflammatory cytokines such $\mathrm{C}-\mathrm{X}-\mathrm{C}$ motif chemokine ligand 10 (CXCL10) that were differentially expressed in unexposed IFN $\gamma$-stimulated BMDMs, remained dysregulated by a similar fold-change magnitude when the IFN $\gamma$-stimulated BMDMs were exposed to Toxoplasma (IRH), suggesting an inability by the parasite to overcome most of the IFN $\gamma$-induced transcriptional changes. Arginase 2 (ARG2) was among 13 genes that were highly expressed in $\mathrm{RH}$ but downregulated in IFN $\gamma$-stimulated BMDMs. Similarly, 60 genes, including the C-C motif chemokine 22 (CCL22), were upregulated in $\mathrm{RH}$ but downregulated by a difference of more than 2-fold change between in $\mathrm{RH}$ and IRH BMDMs.

To gain greater insights into the biological processes underpinning bovine BMDMs transcriptional response to Toxoplasma, and to determine whether the transcriptional changes in the different BMDM conditions was due to differences in the induction of distinct gene sets or the magnitude of induction of the same gene sets, we performed a pre-ranked gene set enrichment analysis (GSEA) (Subramanian et al., 2005) on the differentially expressed genes in IFN $\gamma$-stimulated, IRH, and RH BMDMs using the curated "HALLMARK" gene set database (Liberzon et al., 2015). Several "HALLMARK" gene sets, including the interferon gamma response, inflammatory response, and the regulation of cytokine production, were significantly $(F D R \leq 0.05)$ enriched in at least two BMDM conditions. Some gene sets, including hypoxia, which is not only a well-established Toxoplasma-induced host cell response, but also supports intracellular parasite growth (Wiley et al., 2010), were significantly enriched in RH but absent in IRH (Figure 2C). Thus, infection of naïve and IFN $\gamma$-stimulated
BMDMs modulated by differences in the induction of unique and common gene sets.

\section{IFN $\gamma$ Reverses Toxoplasma-Induced Dysregulation of Genes Linked to Inflammatory and Metabolic Pathways to Restrict Parasite Replication in Bovine Macrophages}

As demonstrated above, Toxoplasma significantly dysregulate several bovine genes, potentially to support its intracellular survival. We reasoned that since IFN $\gamma$-stimulated BMDMs are refractory to the parasite, Toxoplasma-induced genes that support the intracellular parasite lifestyle are likely to be targeted and reversed when BMDMs are pre-stimulated with IFN $\gamma$ prior to infection. Several inflammatory genes were dysregulated in IRH but not in RH BMDMs. For example, CXCL9, 10, and 11, were 22-, 10-, and 12-fold, respectively, upregulated in IRH, but not dysregulated in RH, BMDMs. Markers for the Toxoplasmarefractory classically activated macrophages, such as CD180, $C D 74$, and $C D 1 D$ were highly expressed in IRH but not in RH BMDMs. Similarly, c-type lectins including CLEC6A, which are associated with classically activated macrophages (Jensen et al., 2011; Murray et al., 2014), were upregulated in IRH BMDMs. Conversely, calcium signaling genes that are reported to play a significant role in intracellular parasite survival, such as $C A M K 2 G$, and histone deacetylase $(H D A C) 5$, and 7 , were downregulated in $\mathrm{RH}$, but remained unchanged in IRH BMDMs. A functional analysis on genes upregulated or unchanged in IRH BMDMs revealed an enrichment for, among others, calcium signaling pathway, phospholipase D signaling, defense response 


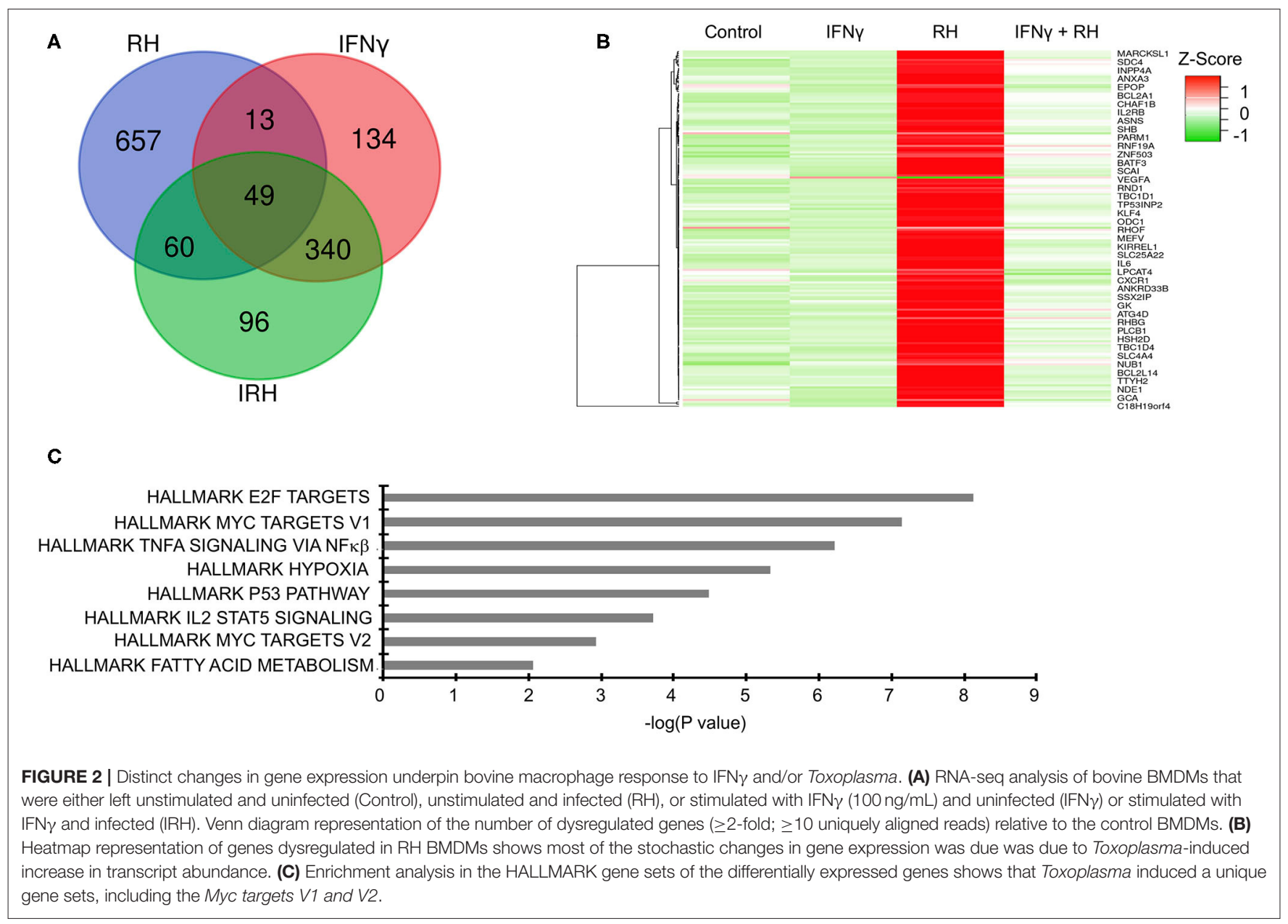


(Figure 3A).

Genes implicated in chemotaxis or anti-inflammatory responses were differentially expressed by a margin of more than 2-fold change between RH and IRH BMDMs. For example, chemotaxis-related CCL22 and CCL24 chemokines were upregulated by 20 - and 12 -fold in $\mathrm{RH}$ but upregulated by 14and 8 -fold in IRH BMDMs. Similarly, the chemokine receptor (CCR7) was upregulated by 26 -fold in RH but not differentially expressed in IRH BMDMs. The anti-inflammatory-related suppressor of cytokine signaling (SOCS) 3, and TNF receptorassociated factor 1 (TRAF1) were also upregulated in $\mathrm{RH}$ but downregulated in IRH BMDMs. Mitogen-activated protein kinases (MAPK), including MAP3K14 and MAP4K1, which induce non-canonical (Jin et al., 2014) and suppresses canonical (Brenner et al., 2005) NF-кB signaling pathways, respectively, were upregulated in $\mathrm{RH}$ but downregulated in IRH BMDMs. Studies in model animals, including mice, have shown that Toxoplasma induces alternative macrophage activation to favor its intracellular lifestyle (Melo et al., 2011). Arginine metabolism, via arginase, is key to alternative macrophage activation. Congruently, Arginase 2 (ARG2) was 4-fold upregulated in $\mathrm{RH}$ but virtually not expressed in IRH BMDMs. Additional genes associated with alternative macrophage activation, such as KLF4 and IL34 were upregulated in RH but downregulated in IRH BMDMs. The expression of protein arginine methyltransferase 5 (PRMT5), which is necessary in c-MYC-mediated alternative macrophage differentiation, was slightly increased in $\mathrm{RH}$ BMDMs. Similarly, genes encoding glucose transporters were upregulated in RH but not IRH BMDMs. Solute carriers $(S L C)$, including $S L C 2 A 1$ and SLC2A3 that encode glucose transporters, were downregulated in IRH but upregulated in RH BMDMs. Other solute carriers, including SLC7A1 and SLC7A5 that function in the L-arginine transport pathway, and $O D C 1$, the rate limiting enzyme in polyamine biosynthesis and a negative regulator of macrophage inflammation (Hardbower et al., 2017), were upregulated in RH BMDMs. Toxoplasma reportedly rely on host lipid droplets, which increase in abundance in Toxoplasma-infected cells, to sustain rapid intracellular replication (Gomes et al., 2014). The expression of pentraxin 3 (PTX3), which is induced by lipid accumulation (Liu et al., 2014), was increased 8-fold in RH but unexpressed in IRH BMDMs. Similarly, the expression of genes involved in fatty acid elongation, such as ELOVL6, were upregulated in $\mathrm{RH}$ but not expressed in IRH BMDMs. Genes upregulated in $\mathrm{RH}$ but not IRH BMDMs were significantly $(F D R \leq 0.05)$ linked to purine 


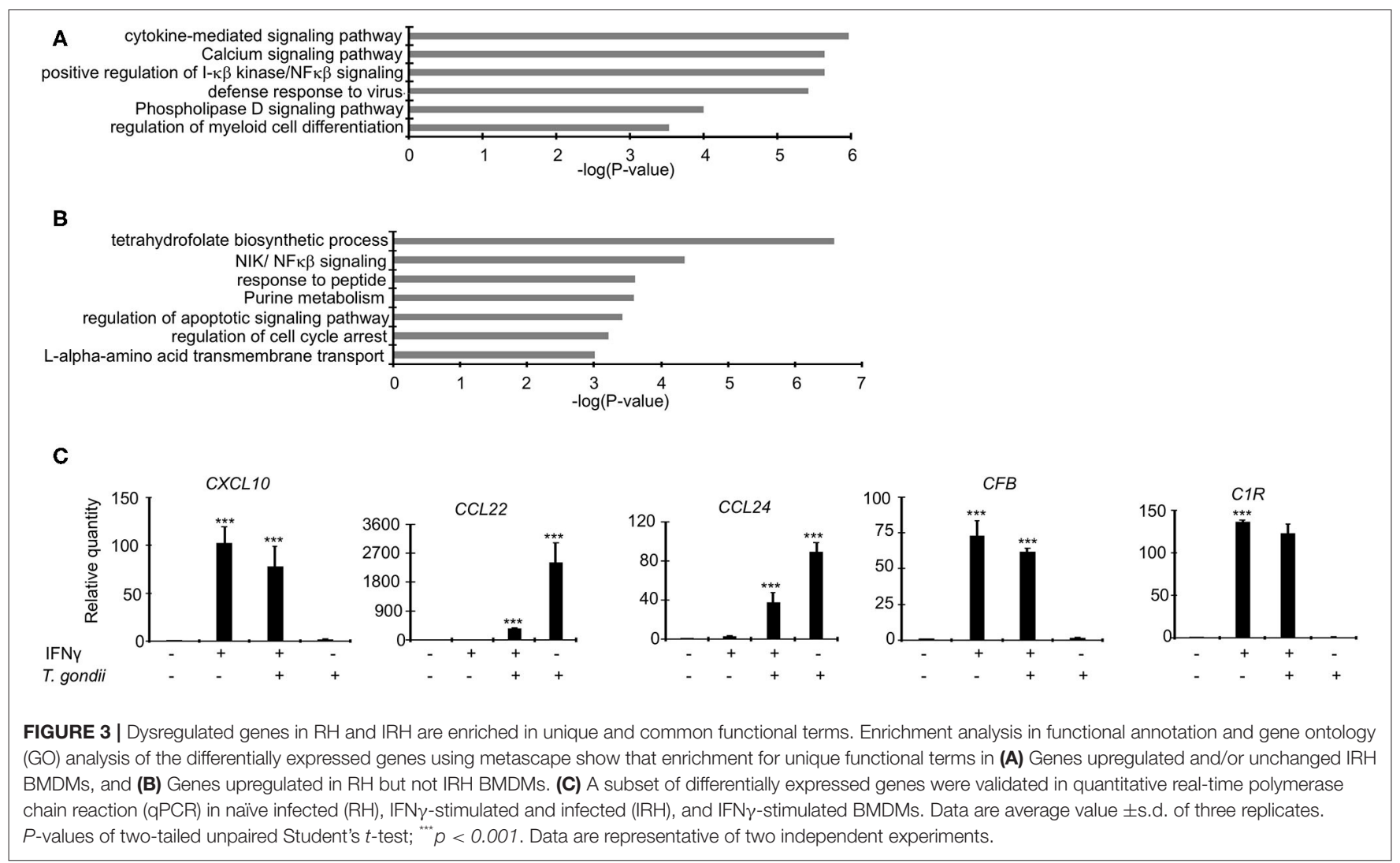

metabolism, NIK/NFK $\beta$ (non-canonical NFк $\beta$ ) signaling, and regulation of apoptotic signaling pathway (Figure 3B), all of which are expected to play a role in regulating Toxoplasma's intracellular fate (Yamamoto et al., 2011; Blume and Seeber, 2018). Quantitative RT-PCR (qPCR) confirmed the differential expression of genes, including CXCL10, CCL22, and CCL24 that are reportedly upregulated in Toxoplasma-infected murine macrophages (Melo et al., 2013), in the different macrophage conditions (Figure 3C and Supplementary Figure 1). Thus, IFN $\gamma$ targets both the host cell inflammatory and metabolic pathways to revoke intracellular parasite replication.

\section{IFN $\gamma$ Abrogates Toxoplasma-Induced $W n t / \beta$-Catenin Signaling in Bovine Macrophages}

Recent studies have documented Toxoplasma-induced expression of several chemokines, including CCL17, CCL22, and CCL24 (He et al., 2018; Majumdar et al., 2019) via the activation of the $W n t / \beta$-catenin signaling pathway (He et al., 2018). Wnt/ $\beta$-catenin-signaling has an important role in various cellular processes, including proliferation (Reya et al., 2003) and immunity (Staal et al., 2008). The variable expression of CCL22 and CCL24, in RH and IRH BMDMs, prompted us to investigate the expression of $W n t$-target genes to establish a role of $W n t / \beta$ catenin signaling in bovine BMDM response to Toxoplasma. However, apart from the downregulation of delta like canonical Notch ligand $1(D L L 1)$ in IFN $\gamma$-stimulated BMDMs, none of the canonical Wnt-target genes were differentially expressed in $\mathrm{RH}$ and/or IRH BMDMs.

Unlike Toxoplasma, IFN $\gamma$ is known to suppress $W n t / \beta$ catenin signaling (Nava et al., 2014; Bai et al., 2017). To determine whether Toxoplasma growth restriction in IFN $\gamma$ stimulated bovine BMDMs is linked to $W n t / \beta$-catenin signaling, we evaluated parasite burden in naïve or IFN $\gamma$-stimulated BMDMs cultured in the presence or absence of a $W n t / \beta$ catenin antagonist (IWR-1-endo). IWR-1-endo reduced parasite burden in naïve BMDMs in a dose-dependent manner without abolishing the differences in parasite burden between naïve and IFN $\gamma$-stimulated BMDMs (Figure 4A). Toxoplasma-induced accumulation of $\beta$-catenin in the host cell nucleus, and the dysregulation of CCL22 is reportedly induced by a dense granule (GRA) protein (GRA18) that is secreted beyond the parasites' parasitophorous vacuole membrane (PVM) into the host cell during infection (He et al., 2018). Thus, to overcome the potential effect of IWR-1-endo on unrelated host cell functions and establish a direct link between infection and $W n t / \beta$-catenin activation, we infected naïve or IFN $\gamma$-stimulated BMDMs with a mutant Toxoplasma strain (RH $\triangle A S P 5)$ and quantified parasite burden using qPCR. The RH $\triangle A S P 5$ mutant strain lacks the ASP5 enzyme that is essential for the processing of GRA proteins, including GRA18, that are destined for secretion into the host cell (Coffey et al., 2015; Hammoudi et al., 2015; Curt-Varesano et al., 2016; He et al., 2018). We reasoned that if GRAs that are secreted in the host cell interact with $\beta$-catenin to induce chemokine secretion and support intracellular parasite survival 
and replication in bovine BMDMs, then the RH $\triangle A S P 5$ strain should not be able to replicate efficiently in naïve BMDMs. Indeed, parasite burden was significantly reduced in naïve BMDMs infected with RH $\triangle A S P 5$, relative to the wildtype (Figure 4B). Unlike wildtype parasites, IWR-1-endo did not significantly alter parasite burden in naïve or IFN $\gamma$-stimulated BMDMs infected with RH $\triangle A S P 5$ (Figure 4C). Neither did IWR-1-endo abrogate intracellular RH $\triangle A S P 5$ burden differences between naïve and IFN $\gamma$-stimulated BMDMs. Finally, when infected with RH $\triangle A S P 5$, but not the wildtype parental strain, naïve BMDMs exhibited high abundance for CCL22 transcripts (Figure 4D). Together, these results indicate a role for $W n t / \beta$ catenin signaling and parasite secreted GRAs that translocate to the host cell in bovine BMDMs anti-Toxoplasma responses.

\section{Parasites in IFN $\gamma$-Stimulated Bovine Macrophages Transcribe Mostly Bradyzoite-Related Genes}

To evaluate whether the infection of bovine BMDMs is underpinned by distinct parasite expression signatures, we used the RNA-sequencing reads uniquely aligning to the parasite genome (GT1 v.46) to evaluate stochastic changes in Toxoplasma transcript abundance in naïve and IFN $\gamma$-stimulated BMDMs. We focused our analysis on genes that were modulated by more than 3-fold change and had more than 10 uniquely aligned RNA-sequencing reads in at least two samples when comparing parasites infecting naïve and IFN $\gamma$-stimulated BMDMs. One hundred and eighty one genes were differentially expressed, of which 94 corresponded to genes upregulated in IFN $\gamma$ stimulated BMDMs (Figure 5 and Supplementary Table 1). Parasite genes that were highly expressed when the parasite is in IFN $\gamma$-stimulated BMDMs included DnaK-tetratricopeptide repeat (DnaK-TPR) and Cyclic AMP-Dependent Protein Kinase Subunit 3 ( $c A M P K 3)$, which are associated with or involved in stress-induced Toxoplasma stage conversion from the fast dividing tachyzoite to the semi-dominant bradyzoite parasite stage (Ueno et al., 2011; Sugi et al., 2016). Thus, consistent with the well-defined immune pressure-induced parasite stage conversion, Toxoplasma potentially responds to the IFN $\gamma$ induced immune pressure by slowing down its rate of replication.

\section{DISCUSSION}

The outcome of Toxoplasma infections in cattle is fundamentally different from that of rodents, small ruminants, and pigs: clinical disease in naturally infected cattle are rare and many largescale studies have failed to detect viable parasites in bovine tissues (Stelzer et al., 2019), suggesting that, like humans, cattle are largely an end-stage host for the parasite. However, the mechanisms underlying bovine resistance to Toxoplasma are largely unknown. In this study, we performed high throughput functional genomics and parasitological assays to investigate the molecular factors that modulate Toxoplasma interactions with bovine bone marrow-derived macrophages (BMDMs). Similar to observations in rodent and human macrophages, interferon gamma (IFN $\gamma$ ) significantly enhanced intracellular parasite growth restriction in bovine BMDMs. Interestingly, despite the ability to restrict intracellular parasite growth, IFN $\gamma$ on its own was not able to induce nitric oxide (NO) secretion in bovine BMDMs, indicating that, unlike murine BMDMs, IFN $\gamma$-induced toxoplasmastatic activities in bovine BMDMs are independent of NO. Additionally, we found that secreted parasite dense granule proteins potentially induce the expression of chemokines, including CCL22, to enhance parasite growth in naïve bovine BMDMs.

Understanding the mechanisms of innate recognition and response to Toxoplasma in mice has been invaluable in advancing knowledge on response to Toxoplasma in other vertebrates, including cattle. The IFN $\gamma$-induced murine antiToxoplasma effectors, which are largely dependent on the activation of immunity-related GTPases (IRGs) and guanylate binding proteins (GBPs), are well-characterized. However, cattle, like humans, lack functional toll-like receptor (TLR) 11 and 12 (O'Neill et al., 2013) that facilitate the recognition of Toxoplasmaderived pathogen-associated molecular patterns (PAMPs) in murine cells (Melo et al., 2010). Although bovine BMDMs express a functional TLR5, unlike murine TLR5, it does not recognize Toxoplasma antigens (Tombácz et al., 2018). Thus, the mechanisms by which bovine cells recognize and respond to Toxoplasma are equivocal and potentially different from those defined in the murine system. Previous studies, including our own (Jensen et al., 2013; Hassan et al., 2015), show that reactive oxygen and nitrogen species, including $\mathrm{NO}$, are central to Toxoplasma growth inhibition in murine macrophages synergistically activated with IFN $\gamma$ and LPS or TNF. Bovine macrophages are known to secrete significantly more NO in response to LPS than sheep and pigs, which are susceptible to Toxoplasma, LPS (Jungi et al., 1996; Young et al., 2018), suggesting that species-specific differences in susceptibility to Toxoplasma is due to differences in NO production. Although parasite growth was significantly restricted in stimulating bovine BMDMs with IFN $\gamma$-stimulated bovine BMDMs, IFN $\gamma$, on it's own, did not induce NO in bovine BMDMs, which is consistent with previous observations (Denis et al., 2005; Young et al., 2018; Imrie and Williams, 2019). In fact, intracellular parasite burden in IFN $\gamma$ - and IFN $\gamma+$ LPS-stimulated BMDMs were similar, despite the latter secreting significantly more NO. Combined, these results suggest that $\mathrm{NO}$ is dispensable in IFN $\gamma$ induced bovine BMDM toxoplasmastatic activities. A similar non-essential role for NO in macrophage response to Toxoplasma has previously been observed in human macrophages. However, human macrophages are distinct from bovine BMDMs, since NO cannot be induced by conventional activating regimes in vitro in human macrophages (Schneemann and Schoedon, 2002).

Recent studies have documented a role for $W n t / \beta$ catenin signaling in host responses to Toxoplasma. Enhanced intracellular Toxoplasma growth was found to co-occur with increased $\beta$-catenin (CTNNB1) gene expression in human cells (Majumdar et al., 2019), while a parasite secreted GRA protein is reported to stabilize $\beta$-catenin in murine BMDMs leading to an increased expression of chemokines such as CCL22 (He et al., 2018; Majumdar et al., 2019). Consistent with IFN $\gamma$-induced inhibition of the $W n t / \beta$-catenin signaling 
A

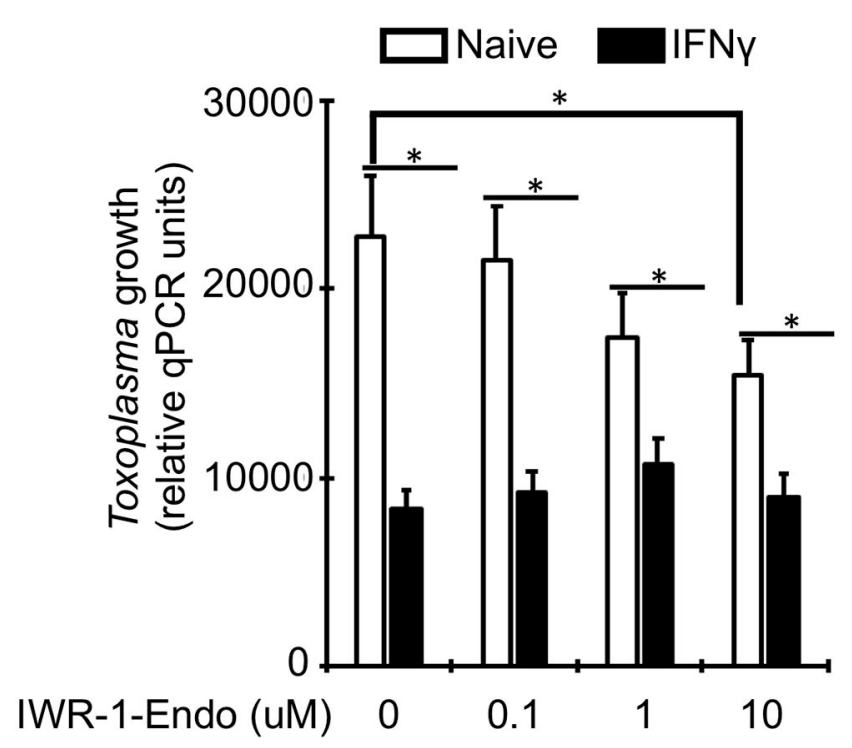

C

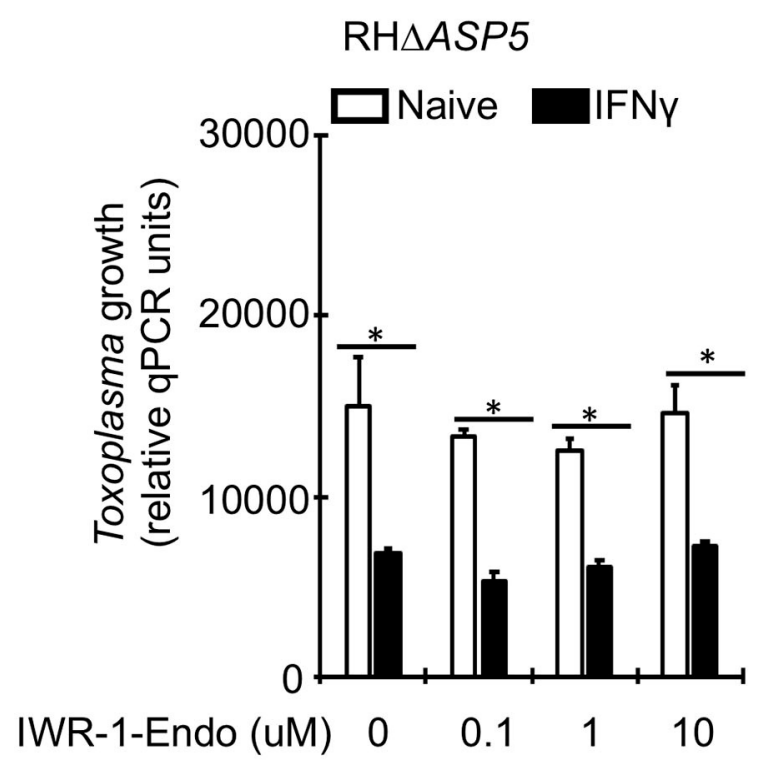

B

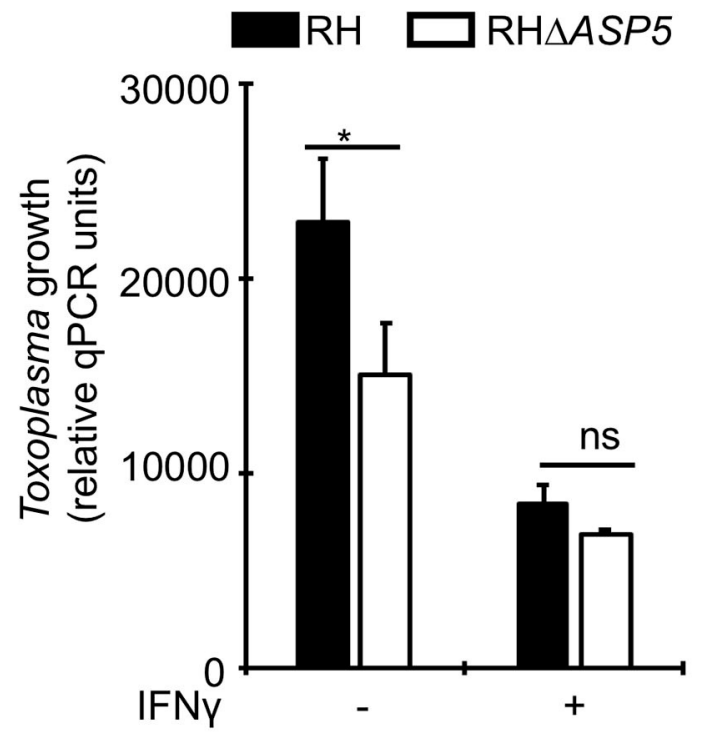

D

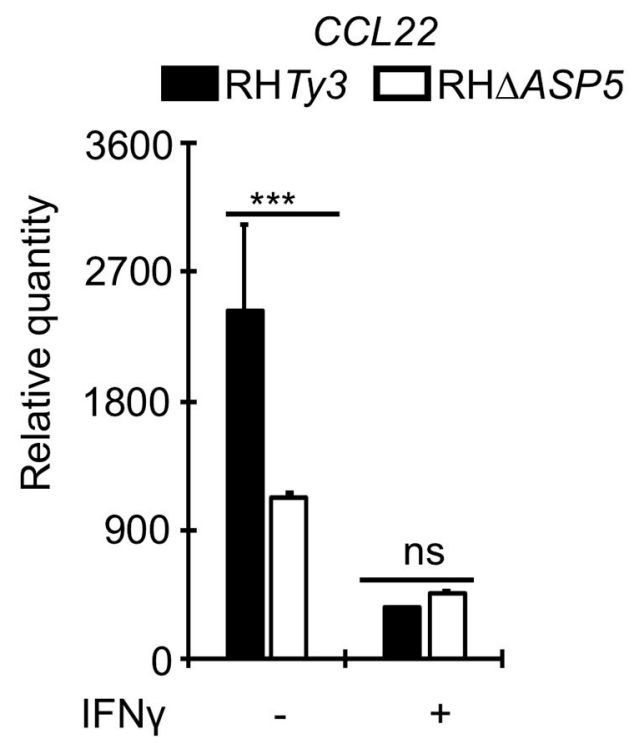

FIGURE 4 | A role for Wnt/ $\beta$-catenin signaling in the IFN $\gamma$-induced response to Toxoplasma in bovine macrophages. (A) Naïve (white bars) or IFN $\gamma$-stimulated (black bars) were cultured overnight with or without increasing concentrations of the Wnt/ $\beta$-catenin signaling antagonist IWR-1-endo and infected with a parental wildtype (RHTy3) Toxoplasma strains. IWR-1-endo did not abolish differences in intracellular parasite burden between naïve and IFN $\gamma$-stimulated BMDMs. (B) The growth of the knockout $\mathrm{RH} \triangle A S P 5$ parasite strain was significantly inhibited in naïve BMDMs infected, relative to the wildtype. $\mathrm{RH} \triangle A S P 5$ parasites do not secrete most dense granule proteins, including GRA18, beyond the parasitophorous vacuole membrane. (C) Unlike wildtype parasites, IWR-1-endo did not significantly alter parasite burden in naïve or IFN $\gamma$-stimulated BMDMs infected with $\mathrm{RH} \triangle A S P 5$. (D) The parental RHTy3 strain induced significantly higher expression of CCL22 in naïve BMDMs when compared to the knockout $\mathrm{RH} \triangle A S P 5$ strain. Data are average value \pm s.d. of three replicates. $P$-values of two-tailed unpaired Student's $t$-test; ${ }^{*} p<0.05$,

${ }^{\star * *} p<0.001$ and $\mathrm{ns}=$ not significant. Data are representative of three independent experiments.

pathway (Nava et al., 2014; Bai et al., 2017), we observed a downregulation of several $W n t / \beta$-catenin signaling-associated genes, including CCL17, CCL22, and CCL24 (He et al., 2018), in IFN $\gamma$-stimulated BMDMs. Congruently, a $W n t / \beta$-catenin signaling chemical inhibitor (IWR-1-endo) reduced intracellular parasite burden in naïve BMDMs in a dose-dependent manner. 


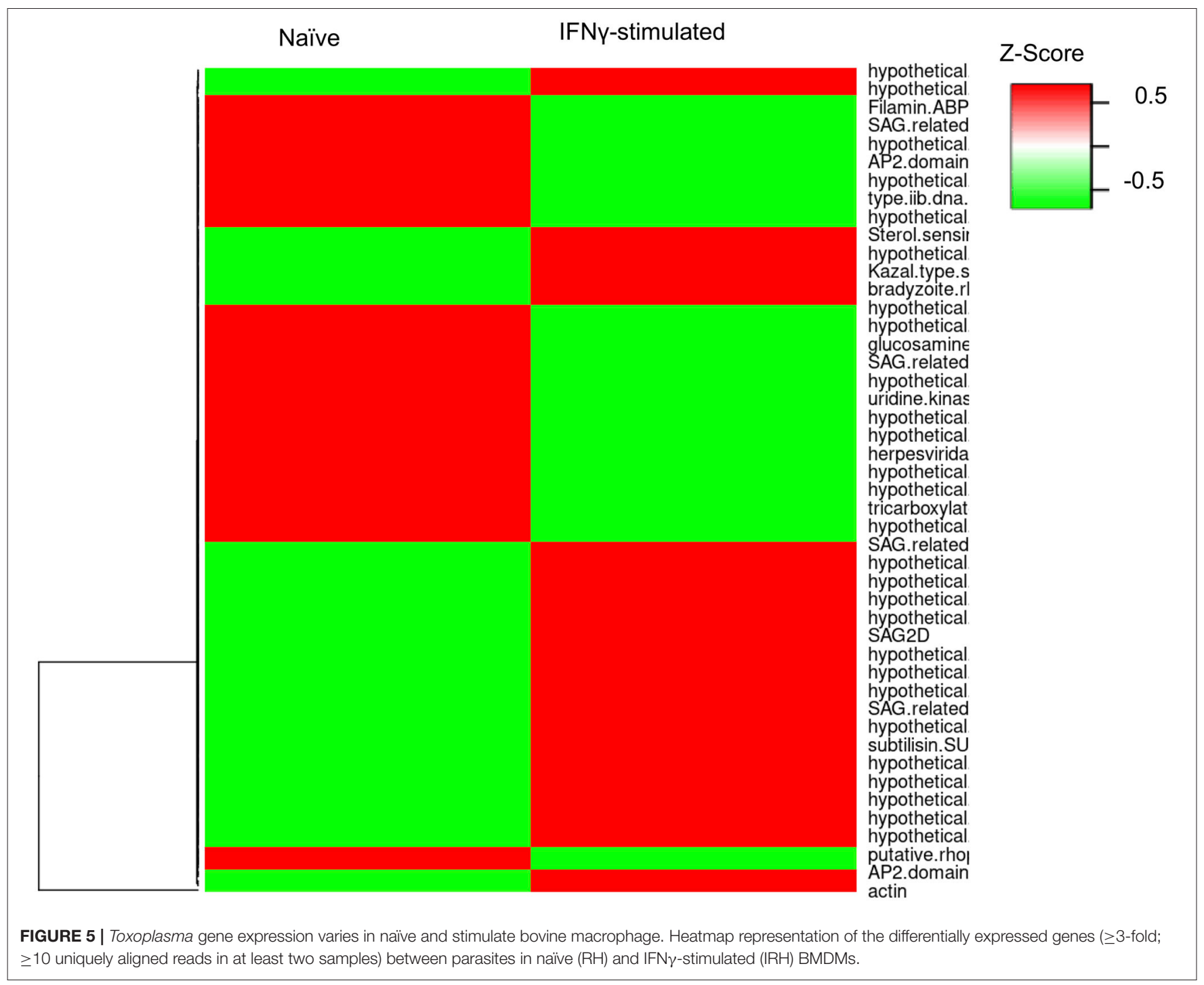

However, IWR-1-endo did not abolish intracellular parasite burden differences between naïve and IFN $\gamma$-stimulated BMDMs, probably because IFN $\gamma$ suppresses $W n t / \beta$-catenin signaling to a level below which further inhibition produces no discernible effect. Considering that we used a single IFN $\gamma$ concentration $(100 \mathrm{ng} / \mathrm{mL})$, it is plausible that IWR-1-endo would have an effect at lower IFN $\gamma$ concentrations. A more plausible explanation for the lack of IWR-1-endo efficacy in IFN $\gamma$ stimulated cells is that besides the $W n t / \beta$-catenin signaling, IFN $\gamma$ induces additional effector mechanisms against the parasite. Although GRA18 is reported to induce $\beta$-catenin accumulation in the host cell nucleus, this was not discernible when GRA18 was expressed at physiological levels (He et al., 2018), which may partly explain the lack of $\beta$-catenin nuclear accumulation in the present study. Nevertheless, intracellular parasite burden in bovine BMDMs infected with a mutant Toxoplasma strain that does not secrete GRA18 into the host cell cytoplasm (RH $\triangle A S P 5)$ (He et al., 2018), was significantly different from cells infected the wildtype parasites. Similar to IWR-1-endo, infection with RH $\triangle A S P 5$ did not abolish intracellular parasite burden differences between naïve and IFN $\gamma$-stimulated BMDMs.

The mechanisms regulating the impact of $W n t / \beta$-catenin on intracellular Toxoplasma replication are largely equivocal. Recent studies indicate that $\beta$-catenin alters intracellular parasite growth dynamics by interacting with indoleamine 2,3-dioxygenase 1 (IDO1): IDO1 promoter activity is supported by $\beta$-catenin. IDO1 is an IFN $\gamma$-inducible protein that degrades tryptophan to kynurenine and is known to impede Toxoplasma growth in human fibroblasts (Pfefferkorn, 1984), epithelial, and endothelial cells (MacKenzie et al., 2007) in vitro. Because IDO1 degrades tryptophan, which supports intracellular Toxoplasma replication, increased IDO1 promoter activity in the presence of $\beta$ catenin may appear contradictory. However, IDO1 transcript and protein levels are often discordant in Toxoplasma-infected cells: Toxoplasma promotes the degradation of IDO1 protein 
(Majumdar et al., 2019). Although we cannot conclude, from this study, that tryptophan plays an essential role in bovine BMDM response to Toxoplasma, IDO1 was significantly downregulated in naïve BMDMs exposed to Toxoplasma. In the absence of IDO1, tryptophan is catabolized to melatonin, which scavenges reactive oxygen species (ROS) and promotes cell survival (Dolado and Nebreda, 2008), both of which are beneficial for intracellular Toxoplasma survival. However, considering that NO and ROS are dispensable for Toxoplasma growth restriction in bovine BMDMs, scavenging of ROS is unlikely to be a viable mechanism by which $\beta$-catenin can affect parasite replication. Rather, it is plausible that melatonin promotes cell survival, which in turn promotes intracellular parasite survival. Indeed, we did not observe significant changes in cell viability in Toxoplasmainfected, relative to uninfected, BMDMs. Alternatively, $W n t / \beta$ catenin-mediated anti-Toxoplasma mechanisms may involve the induction of alternative macrophage activation, which is supportive of intracellular Toxoplasma survival and growth (Melo et al., 2011). Besides, the expression of Wnt/ $\beta$-cateninassociated chemokines, we observed increased expression of genes associated with alternatively activated or foamy macrophages, such as KLF4, ARG2, ODC1, and PTX3, in naive, but not IFN $\gamma$-stimulated, BMDMs. Combined, with the increased expression of glucose transporters in naïve BMDMs, which is reversed in IFN $\gamma$-stimulated BMDMs, we conclude that Toxoplasma exploits the bovine BMDMs metabolic pathways to enhance intracellular survival and replication. It is worth noting that we have tested only one clonal parasite strain $(\mathrm{RH})$ at a single MOI and that different Toxoplasma strains, including the genetically distinct atypical strains such as GUYDOS, and higher MOIs may induce significantly different responses in the bovine BMDMs.

\section{DATA AVAILABILITY STATEMENT}

The original contributions presented in the study are publicly available. This data can be found here: https://www.ncbi.nlm.nih. gov/ PRJNA646376.

\section{REFERENCES}

Bai, M., Li, W., Yu, N., Zhang, H., Long, F., and Zeng, A. (2017). The crosstalk between $\beta$-catenin signaling and type I, type II and type III interferons in lung cancer cells. Am. J. Transl. Res. 9, 2788-2797.

Basavaraju, A. (2016). Toxoplasmosis in HIV infection: an overview. Trop. Parasitol. 6, 129-135. doi: 10.4103/2229-5070.190817

Blume, M., and Seeber, F. (2018). Metabolic interactions between Toxoplasma gondii and its host. F1000Res. 7:F1000. doi: 10.12688/f1000research. 16021.1

Bougdour, A., Durandau, E., Brenier-Pinchart, M. P., Ortet, P., Barakat, M., Kieffer, S., et al. (2013). Host cell subversion by Toxoplasma GRA16, an exported dense granule protein that targets the host cell nucleus and alters gene expression. Cell Host Microbe 13, 489-500. doi: 10.1016/j.chom.2013.03.002

Bray, N. L., Pimentel, H., Melsted, P., and Pachter, L. (2016). Nearoptimal probabilistic RNA-seq quantification. Nat. Biotechnol. 34, 525-527. doi: $10.1038 /$ nbt.3519

\section{ETHICS STATEMENT}

The animal study was reviewed and approved by the Protocols and Ethics Committees of The Roslin Institute, The University of Edinburgh, and the Royal (Dick) School of Veterinary Medicine. In accordance with the United Kingdom Animal (Scientific Procedures) Act 1986, this study did not require a Home Office project license as no regulated procedures were carried out.

\section{AUTHOR CONTRIBUTIONS}

$\mathrm{MH}$ conceived and designed the experiments and wrote the manuscript. $\mathrm{MH}$ and $\mathrm{AG}$ performed the experiments and analyzed the data. All authors contributed to the article and approved the submitted version.

\section{FUNDING}

MH was funded by a University of Edinburgh Chancellor's Fellowship and a Bill and Melinda Gates Foundation award to the Centre for Tropical Livestock Genetics and Health (OPP1127286). The Roslin Institute receives strategic investment funding from the Biotechnology and Biological Sciences.

\section{ACKNOWLEDGMENTS}

The authors thank the University of Edinburgh Genomics Core for providing facilities and services.

\section{SUPPLEMENTARY MATERIAL}

The Supplementary Material for this article can be found online at: https://www.frontiersin.org/articles/10.3389/fcimb. 2020.00437/full\#supplementary-material

Supplementary Figure 1 | Quantitative real-time polymerase chain reaction (qPCR) of some differentially expressed genes in naïve infected ( $\mathrm{RH}$; black bars), IFN $\gamma$-stimulated and infected (IRH; blue bars), and IFN $\gamma$-stimulated (red bars), unstimulated-uninfected control (open bars) BMDMs. Data are average value \pm s.d. of three replicates. Data are representative of two independent experiments.

Brenner, D., Golks, A., Kiefer, F., Krammer, P. H., and Arnold, R. (2005). Activation or suppression of NFKB by HPK1 determines sensitivity to activation-induced cell death. EMBO J. 24, 4279-4290. doi: 10.1038/sj.emboj.7600894

Channon, J. Y., Seguin, R. M., and Kasper, L. H. (2000). Differential infectivity and division of Toxoplasma gondii in human peripheral blood leukocytes. Infect. Immun. 68, 4822-4826. doi: 10.1128/IAI.68.8.4822-48 26.2000

Cirelli, K. M., Gorfu, G., Hassan, M. A., Printz, M., Crown, D., Leppla, S. H., et al. (2014). Inflammasome sensor NLRP1 controls rat macrophage susceptibility to Toxoplasma gondii. PLoS Pathog. 10:e1003927. doi: 10.1371/journal.ppat.1003927

Coffey, M. J., Sleebs, B. E., Uboldi, A. D., Garnham, A., Franco, M., Marino, N. D., et al. (2015). An aspartyl protease defines a novel pathway for export of Toxoplasma proteins into the host cell. elife 4:e10809. doi: 10.7554/eLife.10809.025

Curt-Varesano, A., Braun, L., Ranquet, C., Hakimi, M. A., and Bougdour, A. (2016). The aspartyl protease TgASP5 mediates the export of the Toxoplasma 
GRA16 and GRA24 effectors into host cells. Cell Microbiol. 18, 151-167. doi: $10.1111 / \mathrm{cmi} .12498$

De Paoli, F., Staels, B., and Chinetti-Gbaguidi, G. (2014). Macrophage phenotypes and their modulation in atherosclerosis. Circ. J. 78, 1775-1781. doi: 10.1253/circj.CJ-14-0621

Denis, M., Wedlock, D. N., and Buddle, B. M. (2005). IFN- $\gamma$ enhances bovine macrophage responsiveness to Mycobacterium bovis: impact on bacterial replication, cytokine release and macrophage apoptosis. Immunol. Cell Biol. 83, 643-650. doi: 10.1111/j.1440-1711.2005.01386.x

Dolado, I., and Nebreda, A. R. (2008). AKT and oxidative stress team up to kill cancer cells. Cancer Cell 14, 427-429. doi: 10.1016/j.ccr.2008.11.006

Dubey, J. P. (1986). A review of toxoplasmosis in cattle. Vet. Parasitol. 22, 177-202. doi: 10.1016/0304-4017(86)90106-8

Dunay, I. R., and Sibley, L. D. (2010). Monocytes mediate mucosal immunity to Toxoplasma gondii. Curr. Opin. Immunol. 22, 461-466. doi: 10.1016/j.coi.2010.04.008

Esteban-Redondo, I., and Innes, E. A. (1997). Toxoplasma gondii infection in sheep and cattle. Comp. Immunol. Microbiol. Infect. Dis. 20, 191-196. doi: 10.1016/S.0147-9571(96)00039-2

FAO/WHO (2014). Multicriteria-Based Ranking for Risk Management of Food-Borne Parasites. Available online at: http://www.fao.org/3/a-i3649e.pdf \%5Cnfiles/540/a-i3649e.pdf (accessed August 9, 2020).

Fleckenstein, M. C., Reese, M. L., Konen-Waisman, S., Boothroyd, J. C., Howard, J. C., and Steinfeldt, T. (2012). A Toxoplasma gondii pseudokinase inhibits host IRG resistance proteins. PLoS Biol. 10:e1001358. doi: 10.1371/journal.pbio.1001358

Gazzinelli, R. T., Hieny, S., Wynn, T. A., Wolf, S., and Sher, A. (1993). Interleukin 12 is required for the T-lymphocyte-independent induction of interferon $\gamma$ by an intracellular parasite and induces resistance in T-cell- deficient hosts. Proc. Natl. Acad. Sci. U.S.A. 90, 6115-6119. doi: 10.1073/pnas.90.13.6115

Gazzinelli, R. T., Wysocka, M., Hayashi, S., Denkers, E. Y., Hieny, S., Caspar, P., et al. (1994). Parasite-induced IL-12 stimulates early IFN-gamma synthesis and resistance during acute infection with Toxoplasma gondii. J. Immunol. 153, 2533-2543.

Gkogka, E., Reij, M. W., Havelaar, A. H., Zwietering, M. H., and Gorris, L. G. M. (2011). Risk-based estimate of effect of foodborne diseases on public health, Greece. Emerg. Infect. Dis. 17, 1581-1590. doi: 10.3201/eid1709.101766

Gomes, A. F., Magalhães, K. G., Rodrigues, R. M., De Carvalho, L., Molinaro, R., Bozza, P. T., et al. (2014). Toxoplasma gondii-skeletal muscle cells interaction increases lipid droplet biogenesis and positively modulates the production of IL-12, IFN-g and PGE 2. Parasit. Vectors 7:47. doi: 10.1186/1756-33 $05-7-47$

Gregg, B., Taylor, B. C., John, B., Tait-Wojno, E. D., Girgis, N. M., Miller, N., et al. (2013). Replication and distribution of Toxoplasma gondii in the small intestine after oral infection with tissue cysts. Infect. Immun. 81, 1635-1643. doi: 10.1128/IAI.01126-12

Hammoudi, P. M., Jacot, D., Mueller, C., Di Cristina, M., Dogga, S. K., Marq, J. B., et al. (2015). Fundamental roles of the golgi-associated Toxoplasma aspartyl protease, ASP5, at the host-parasite interface. PLoS Pathog. 11:e1005211. doi: 10.1371/journal.ppat.1005211

Hardbower, D. M., Asim, M., Luis, P. B., Singh, K., Barry, D. P., Yang, C., et al. (2017). Ornithine decarboxylase regulates M1 macrophage activation and mucosal inflammation via histone modifications. Proc. Natl. Acad. Sci. U.S.A. 114, E751-E760. doi: 10.1073/pnas.1614958114

Hassan, M. A., Jensen, K. D., Butty, V., Hu, K., Boedec, E., Prins, P., et al. (2015). Transcriptional and linkage analyses identify loci that mediate the differential macrophage response to inflammatory stimuli and infection. PLOS Genet. 11:e1005619. doi: 10.1371/journal.pgen.1005619

He, H., Brenier-Pinchart, M.-P. P., Braun, L., Kraut, A., Touquet, B., Couté, Y., et al. (2018). Characterization of a Toxoplasma effector uncovers an alternative GSK3/ $\beta$-catenin-regulatory pathway of inflammation. elife 7:e39887. doi: 10.7554/eLife.39887.027

Hill, D., and Dubey, J. P. (2002). Toxoplasma gondii: transmission, diagnosis, and prevention. Clin. Microbiol. Infect. 8, 634-640. doi: 10.1046/j.1469-0691.2002.00485.x

Hunter, C. A., and Sibley, L. D. (2012). Modulation of innate immunity by Toxoplasma gondii virulence effectors. Nat. Rev. Microbiol. 10, 766-778. doi: $10.1038 /$ nrmicro2858
Imrie, H., and Williams, D. J. L. (2019). Stimulation of bovine monocytederived macrophages with lipopolysaccharide, interferon-?, Interleukin-4 or Interleukin-13 does not induce detectable changes in nitric oxide or arginase activity. BMC Vet. Res. 15:45. doi: 10.1186/s12917-019-1785-0

Jensen, K., Kenneth, H., Whitmarsh, R., Hassan, M. A., Julien, L., Lu, D., et al. (2013). Toxoplasma gondii rhoptry 16 kinase promotes host resistance to oral infection and intestinal inflammation only in the context of the dense granule protein GRA15. Infect. Immun. 81, 2156-2167. doi: 10.1128/IAI.01185-12

Jensen, K. D. C., Wang, Y., Wojno, E. D. T., Shastri, A. J., Hu, K., Cornel, L., et al. (2011). Toxoplasma polymorphic effectors determine macrophage polarization and intestinal inflammation. Cell Host Microbe 9, 472-483. doi: 10.1016/j.chom.2011.04.015

Jin, J., Hu, H., Li, H. S., Yu, J., Xiao, Y., Brittain, G. C., et al. (2014). Noncanonical NF- $\mathrm{KB}$ pathway controls the production of type I interferons in antiviral innate immunity. Immunity 40, 342-354. doi: 10.1016/j.immuni.2014. 02.006

Jungi, T. W., Adler, H., Adler, B., Thöny, M., Krampe, M., and Peterhans, E. (1996). Inducible nitric oxide synthase of macrophages. Present knowledge and evidence for species-specific regulation. Vet. Immunol. Immunopathol. 54, 323-330. doi: 10.1016/S0165-2427(96)05690-5

Koshy, A. A., Dietrich, H. K., Christian, D. A., Melehani, J. H., Shastri, A. J., Hunter, C. A., et al. (2012). Toxoplasma co-opts host cells it does not invade. PLoS Pathog. 8:e1002825. doi: 10.1371/journal.ppat.1002825

Li, M. H., Che, T. C., Kuo, T. T., Tseng, C. C. P., and Tseng, C. C. P. (2000). Realtime PCR for quantitative detection of Toxoplasma gondii. J. Clin. Microbiol. 38, 4121-4125. doi: 10.1128/JCM.38.11.4121-4125.2000

Liberzon, A., Birger, C., Thorvaldsdóttir, H., Ghandi, M., Mesirov, J. P., and Tamayo, P. (2015). The molecular signatures database hallmark gene set collection. Cell Syst. 1, 417-425. doi: 10.1016/j.cels.2015.12.004

Liu, W., Jiang, J., Yan, D., Li, D., Li, W., Ma, Y., et al. (2014). Pentraxin 3 promotes oxLDL uptake and inhibits cholesterol efflux from macrophage-derived foam cells. Exp. Mol. Pathol. 96, 292-299. doi: 10.1016/j.yexmp.2014.03.007

MacKenzie, C., Heseler, K., Muller, A., and Daubener, W. (2007). Role of indoleamine 2,3-dioxygenase in antimicrobial defence and immunoregulation: tryptophan depletion versus production of toxic kynurenines. Curr. Drug Metab. 8, 237-244. doi: 10.2174/138920007780362518

MacMicking, J., Xie, Q. W., and Nathan, C. (1997). Nitric oxide and macrophage function. Annu. Rev. Immunol. 15, 323-350. doi: 10.1146/annurev.immunol.15.1.323

Majumdar, T., Sharma, S., Kumar, M., Hussain, M. A., Chauhan, N., Kalia, I., et al. (2019). Tryptophan-kynurenine pathway attenuates $\beta$-catenin-dependent pro-parasitic role of STING-TICAM2-IRF3-IDO1 signalosome in Toxoplasma gondii infection. Cell Death Dis. 10:161. doi: 10.1038/s41419-019-1420-9

Melo, M., Nguyen, Q., Cordeiro, C., Hassan, M., Yang, N., McKell, R., et al. (2013). Transcriptional analysis of murine macrophages infected with different Toxoplasma strains identifies novel regulation of host signaling pathways. PLoS Pathog. 9:e1003779. doi: 10.1371/journal.ppat.1003779

Melo, M. B., Jensen, K. D., and Saeij, J. P. (2011). Toxoplasma gondii effectors are master regulators of the inflammatory response. Trends Parasitol. 27, 487-495. doi: $10.1016 / j . p t .2011 .08 .001$

Melo, M. B., Kasperkovitz, P., Cerny, A., Konen-Waisman, S., KurtJones, E. A., Lien, E., et al. (2010). UNC93B1 mediates host resistance to infection with Toxoplasma gondii. PLoS Pathog. 6:e1001071. doi: 10.1371/journal.ppat.1001071

Morisaki, J. H., Heuser, J. E., and Sibley, L. D. (1995). Invasion of Toxoplasma gondii occurs by active penetration of the host cell. J. Cell Sci. 108, 2457-2464.

Murray, P. J., Allen, J. E., Biswas, S. K., Fisher, E. A., Gilroy, D. W., Goerdt, S., et al. (2014). Macrophage activation and polarization: nomenclature and experimental guidelines. Immunity 41, 14-20. doi: 10.1016/j.immuni.2014.06.008

Nava, P., Kamekura, R., Quirós, M., Medina-Contreras, O., Hamilton, R. W., Kolegraff, K. N., et al. (2014). IFN $\gamma$-induced suppression of $\beta$-catenin signaling: evidence for roles of Akt and 14.3.3ఢ. Mol. Biol. Cell 25, 2894-2904. doi: 10.1091/mbc.e13-09-0512

Niedelman, W., Sprokholt, J. K., Clough, B., Frickel, E. M., and Saeij, J. P. (2013). Cell death of gamma interferon-stimulated human fibroblasts upon Toxoplasma gondii infection induces early parasite egress and limits parasite replication. Infect. Immun. 81, 4341-4349. doi: 10.1128/IAI.00416-13 
O’Neill, L. A. J., Golenbock, D., and Bowie, A. G. (2013). The history of tolllike receptors-redefining innate immunity. Nat. Rev. Immunol. 13, 453-460. doi: $10.1038 /$ nri3446

Pfefferkorn, E. R. (1984). Interferon gamma blocks the growth of Toxoplasma gondii in human fibroblasts by inducing the host cells to degrade tryptophan. Proc. Natl. Acad. Sci. U.S.A. 81, 908-912. doi: 10.1073/pnas.81.3.908

Pimentel, H., Bray, N. L., Puente, S., Melsted, P., and Pachter, L. (2017). Differential analysis of RNA-seq incorporating quantification uncertainty. Nat. Methods 14, 687-690. doi: 10.1038/nmeth.4324

Price, J. V., and Vance, R. E. (2014). The macrophage paradox. Immunity 41, 685-693. doi: 10.1016/j.immuni.2014.10.015

Reya, T., Duncan, A. W., Ailles, L., Domen, J., Scherer, D. C., Willert, K., et al. (2003). A role for wnt signalling in self-renewal of haematopoietic stem cells. Nature 423, 409-415. doi: 10.1038/nature01593

Scharton-Kersten, T. M., Yap, G., Magram, J., and Sher, A. (1997). Inducible nitric oxide is essential for host control of persistent but not acute infection with the intracellular pathogen Toxoplasma gondii. J. Exp. Med. 185, 1261-1273. doi: 10.1084 /jem.185.7.1261

Schneemann, M., and Schoedon, G. (2002). Species differences in macrophage NO production are important. Nat. Immunol. 3:102. doi: 10.1038/ni0202-102a

Sibley, L. D., Adams, L. B., Fukutomi, Y., and Krahenbuhl, J. L. (1991). Tumor necrosis factor-alpha triggers antitoxoplasmal activity of IFN-gamma primed macrophages. J. Immunol. 147, 2340-2345.

Sindrilaru, A., and Scharffetter-Kochanek, K. (2013). Disclosure of the culprits: macrophages-versatile regulators of wound healing. Adv. Wound Care 2, 357-368. doi: 10.1089/wound.2012.0407

Song, H. B., Jun, H. O., Kim, J. H. J. H., Lee, Y. H., Choi, M. H., and Kim, J. H. J. H. (2017). Disruption of outer blood-retinal barrier by Toxoplasma gondii-infected monocytes is mediated by paracrinely activated FAK signaling. PLoS ONE 12:e0175159. doi: 10.1371/journal.pone.01 75159

Staal, F. J. T., Luis, T. C., and Tiemessen, M. M. (2008). WNT signalling in the immune system: WNT is spreading its wings. Nat. Rev. Immunol. 8, 581-593. doi: $10.1038 /$ nri2360

Stelzer, S., Basso, W., Benavides Silván, J., Ortega-Mora, L. M., Maksimov, P., Gethmann, J., et al. (2019). Toxoplasma gondii infection and toxoplasmosis in farm animals: risk factors and economic impact. Food Waterborne Parasitol. 15:e00037. doi: 10.1016/j.fawpar.2019.e00037

Subramanian, A., Tamayo, P., Mootha, V. K., Mukherjee, S., Ebert, B. L., Gillette, M. A., et al. (2005). Gene set enrichment analysis: a knowledge-based approach for interpreting genome-wide expression profiles. Proc. Natl. Acad. Sci. U.S.A. 102, 15545-15550. doi: 10.1073/pnas.0506580102

Sugi, T., Ma, Y. F., Tomita, T., Murakoshi, F., Eaton, M. S., Yakubu, R., et al. (2016). Toxoplasma gondii cyclic AMP-dependent protein kinase subunit 3 is involved in the switch from tachyzoite to bradyzoite development. mBio 7, e 00755-16. doi: 10.1128/mBio.00755-16

Thi, E. P., Lambertz, U., and Reiner, N. E. (2012). Sleeping with the enemy: how intracellular pathogens cope with a macrophage lifestyle. PLoS Pathog. 8:e1002551. doi: 10.1371/journal.ppat.1002551
Tombácz, K., Burgess, G., Holder, A., Werners, A., and Werling, D. (2018). Toxoplasma gondii profilin does not stimulate an innate immune response through bovine or human TLR5. Innate Immun. 24, 422-429. doi: $10.1177 / 1753425918798450$

Tosh, K. W., Mittereder, L., Bonne-Annee, S., Hieny, S., Nutman, T. B., Singer, S. M., et al. (2016). The IL-12 response of primary human dendritic cells and monocytes to Toxoplasma gondii is stimulated by phagocytosis of live parasites rather than host cell invasion. J. Immunol. 196, 345-356. doi: 10.4049/jimmunol.1501558

Ueno, A., Dautu, G., Haga, K., Munyaka, B., Carmen, G., Kobayashi, Y., et al. (2011). Toxoplasma gondii: a bradyzoite-specific DnaK-tetratricopeptide repeat (DnaK-TPR) protein interacts with p23 co-chaperone protein. Exp. Parasitol. 127, 795-803. doi: 10.1016/j.exppara.2011.01.015

van de Vosse, E., van Dissel, J. T., and Ottenhoff, T. H. (2009). Genetic deficiencies of innate immune signalling in human infectious disease. Lancet Infect. Dis. 9, 688-698. doi: 10.1016/S1473-3099(09)70255-5

Wiley, M., Sweeney, K. R., Chan, D. A., Brown, K. M., McMurtrey, C., Howard, E. W., et al. (2010). Toxoplasma gondii activates hypoxia-inducible factor (HIF) by stabilizing the HIF- $1 \alpha$ subunit via type I activin-like receptor kinase receptor signaling. J. Biol. Chem. 285, 26852-26860. doi: 10.1074/jbc.M110.147041

Yamamoto, M., Ma, J. S., Mueller, C., Kamiyama, N., Saiga, H., Kubo, E., et al. (2011). ATF6beta is a host cellular target of the Toxoplasma gondii virulence factor ROP18. J. Exp. Med. 208, 1533-1546. doi: 10.1084/jem.20101660

Ye, J., Coulouris, G., Zaretskaya, I., Cutcutache, I., Rozen, S., and Madden, T. L. (2012). Primer-BLAST: a tool to design target-specific primers for polymerase chain reaction. BMC Bioinf. 13:134. doi: 10.1186/1471-2105-13-134

Young, R., Bush, S. J., Lefevre, L., McCulloch, M. E. B., Lisowski, Z. M., Muriuki, C., et al. (2018). Species-specific transcriptional regulation of genes involved in nitric oxide production and arginine metabolism in macrophages. Immunohorizons 2, 27-37. doi: 10.4049/immunohorizons.1700073

Zhao, Y., Marple, A. H., Ferguson, D. J. P., Bzik, D. J., and Yap, G. S. (2014). Avirulent strains of Toxoplasma gondii infect macrophages by active invasion from the phagosome. Proc. Natl. Acad. Sci. U.S.A. 111, 6437-6442. doi: 10.1073/pnas.1316841111

Zhao, Y. O., Khaminets, A., Hunn, J. P., and Howard, J. C. (2009). Disruption of the Toxoplasma gondii parasitophorous vacuole by IFNgamma-inducible immunity-related GTPases (IRG proteins) triggers necrotic cell death. PLoS Pathog. 5:e1000288. doi: 10.1371/journal.ppat.1000288

Conflict of Interest: The authors declare that the research was conducted in the absence of any commercial or financial relationships that could be construed as a potential conflict of interest.

Copyright (C) 2020 Gossner and Hassan. This is an open-access article distributed under the terms of the Creative Commons Attribution License (CC BY). The use, distribution or reproduction in other forums is permitted, provided the original author(s) and the copyright owner(s) are credited and that the original publication in this journal is cited, in accordance with accepted academic practice. No use, distribution or reproduction is permitted which does not comply with these terms. 